\title{
As Percepções sobre Democracia, Cidadania e Direitos
}

Denise Paiva
Universidade Federal de Goiás
Marta Rovery Souza
Universidade Federal de Goiás
Gustavo de Faria Lopes
Programa de pós-Graduação em Sociologia da
Universidade Federal de Goiás

\section{Resumo}

Os autores analisam as percepções sobre a democracia brasileira com base nas informações sobre o apoio ao sistema político e seu funcionamento, opinião e valores sobre direitos individuais e cidadania, e a percepção sobre os problemas do país. O artigo utiliza os dados do ESEB 2002.

Palavras-chave: Estudo Eleitoral Brasileiro; democracia; cidadania; direitos individuais

\begin{abstract}
The authors analyse the perceptions about the Brazilian democracy, based on the information about the support to the political system and to its dynamics, the values and opinions about citizenship and individual rights, and the perception about the country problems. The data come from 2002 Brazilian Electoral Study.
\end{abstract}

Keywords: Brazilian Electoral Study; democracy; citizenship; individual rights 
Este artigo insere-se na discussão sobre a percepção dos brasileiros quanto ao funcionamento e eficácia da democracia no Brasil. O eixo central da discussão é - grau de apoio e a satisfação com o regime democrático. Para tanto, os indicadores utilizados serão: a) o apoio ao sistema democrático, que envolve questões como a opinião sobre regime de governo, sobre a influência do voto na solução dos problemas do país, sobre a obrigatoriedade do voto e sobre a preferência pela participação popular ou a presença, a partir de uma perspectiva voluntarista, de um líder político para resolver os problemas do país; b) os valores e as concepções quanto aos direitos individuais e cidadania, através de questões que dizem respeito à atuação da justiça, aos partidos políticos e o respeito aos direitos e liberdades individuais; e c) a identificação do maior problema enfrentado pelo Brasil, segundo os entrevistados.

A transição política brasileira foi longa, iniciando-se nos anos setenta e só tendo seu desfecho com as eleições presidenciais de 1989. A mobilização política ocorrida durante esse processo e as mudanças institucionais advindas acenavam com a promessa não só da construção de um regime democrático, mas também de uma sociedade menos desigual. Este era o desafio a ser vencido não só pelo Brasil, mas por todas as chamadas "novas democracias"1.

A expansão das novas democracias motivou estudos sobre a transição de regimes autoritários, dividindo esse processo em duas etapas: a primeira é caracterizada pela criação ou recriação das instituições poliárquicas e a segunda pela consolidação do regime democrático e de seu funcionamento efetivo, tema de discussão deste artigo.

De acordo com O’Donnel, a democracia está consolidada quando existe um "consenso processual" mínimo com relação às instituições poliárquicas, quais sejam, o voto secreto, o sufrágio universal, eleições regulares, competição partidária, acesso e reconhecimento das associações e accountability do Executivo. Nessa definição processual, a democratização das relações sociais, para além da esfera política, não é condição, mas conseqüência eventual do funcionamento habitual e do fortalecimento das instituições poliárquicas (O’DONNEL, 1992, p. 49).

Mais de um século depois da proclamação da República, as dificuldades e interrupções na estabilidade da democracia no Brasil têm sido inúmeras e as

\footnotetext{
1 No decorrer dos anos setenta houve, no país, amplas mobilizações políticas pelo retorno ao regime democrático dentre as quais merecem destaque os movimentos pelo respeito aos direitos humanos, pela anistia e o das "Diretas Já" (SINGER et al, 1980 e SADER, 1988). No que concerne à literatura sobre a transição política nas chamadas novas democracias, incluindo o Brasil, existem várias obras publicadas. Ver, entre outros, O'Donnel e Reis (1988) e Schmitter et al (1988). No âmbito desta discussão estava presente também a preocupação com os possíveis cenários pós-transição. O’Donnel, por exemplo, ao analisar as transições na América Latina, afirma: "Os processos de democratização vividos pelos nossos países implicam em duas transições. A primeira que vai do regime autoritário até a instalação de um regime democrático. A segunda vai deste governo até a consolidação da democracia" (O’DONNEL, 1992, p. 43).
} 
justificativas as mais variadas possíveis. Vão desde o "complexo de clã" herdado pelos brasileiros dos povos ameríndios e africanos, descrito por Oliveira Viana, para justificar a necessidade de um Estado autoritário até as visões tradicionalistas, que viam em nossas origens rurais e ibéricas um obstáculo intransponível para as tentativas de construir uma sociedade democrática (MOISÉS, 1995).

Considerando que o país tem, historicamente, experimentado períodos de democracia e autoritarismo, torna-se importante examinar os indicadores específicos relacionados à atitude do público quanto à valorização da democracia como idéia normativa, isto é, a sua valorização pela superioridade de suas regras e procedimentos. Estes indicadores compõem um traço importante das chances efetivas de consolidação democrática no Brasil.

É importante verificar também, após quase duas décadas da experiência democrática recente, em que medida as promessas se cumpriram e como os desafios foram transpostos. Dessa forma, justifica-se sobremaneira avaliar a confiança nas instituições democráticas, bem como verificar os níveis de satisfação com seu funcionamento e eficácia, observando-se o grau de apoio da sociedade brasileira à democracia.

Essas variáveis permitirão analisar se existe um apoio difuso, e até inconsistente, à democracia, como alguns estudos têm apontado, ou se, ao contrário, é possível observar uma valorização mais sólida das instituições democráticas $^{2}$. Os dados empíricos apresentados adiante fornecem uma visão bastante representativa da sociedade brasileira em relação a este tema, mas o escopo deste artigo não permite o aprofundamento desta discussão.

Existe um amplo debate no âmbito da Ciência Política acerca da relação entre cultura política e instituições, qual seja: o que melhor explica a democracia ${ }^{3}$, o arranjo político-institucional ou a cultura política? A resposta a esta indagação contrapõe duas abordagens que poderíamos denominar procedimental ou nãoculturalista, quando se enfatiza o desenho institucional, e normativa ou culturalista, quando enfatiza o papel da cultura democrática e valoriza a relação entre os conteúdos e resultantes das decisões políticas. Esta abordagem propõe discutir qual o modelo de sociedade pretendido, com uma perspectiva mais substantiva do significado da democracia, que não seria apenas a resultante da engenharia

\footnotetext{
2 Um estudo bastante rico sobre o tema se encontra em Moisés (1995). Ver também Baquero (2002).

3 Não está entre os objetivos deste artigo remontar à vasta discussão existente na teoria democrática acerca dos modelos de democracia. Num sentido amplo, como afirma Held (1996), tais modelos podem ser divididos em dois grandes tipos: democracia direta ou participativa, sistema no qual a tomada de decisão nos negócios envolve os cidadãos de forma direta, e democracia liberal ou representativa, sistema no qual os eleitos representam os interesses dos cidadãos dentro de um arcabouço legal e institucional. Este artigo visa analisar este segundo tipo de democracia.
} 
institucional. A existência de uma cultura democrática seria fundamental para seu surgimento e manutenção ${ }^{4}$.

Existe uma relação de fortalecimento recíproco entre instituições democráticas e cultura política mas não nos interessa aqui discutir a direção da causalidade. Conforme afirma Moisés, “a cultura política é insuficiente per se para gerar as condições necessárias à emergência do regime democrático, isso não autoriza a considerá-la desnecessária ao processo de sua consolidação"(MOISÉS, 1995, p.97).

De acordo com Almond \& Verba (1992), a cultura política refere-se às orientações especificamente políticas, às atitudes relativas ao sistema político, às suas diversas partes e ao papel dos cidadãos na vida pública. Neste sentido, é uma peça valiosa para a legitimidade da democracia, uma vez que diz respeito a um conjunto de valores que são importantes para a manutenção da estabilidade democrática. $O$ arranjo político-institucional garante 0 funcionamento da democracia mas não é capaz de criar per se uma cultura política democrática.

Nosso objetivo ao remeter a esse debate, ainda que muito brevemente, é problematizar em que medida ele pode ajudar a entender o contexto atual da relação entre sociedade e democracia no Brasil. Assim, partindo dos dados analisados, pretende-se fazer algumas considerações de caráter mais geral sobre a democracia brasileira, seus desafios e dilemas atuais.

A democracia - compreendida como um regime no qual se observa a progressiva ampliação da competição e da participação, uma poliarquia, enfim, na acepção de Dahl (1997), capaz de contemplar a realização de eleições livres e competitivas, voto secreto, sufrágio universal, liberdade de organização e expressão - é hoje uma realidade no Brasil. Cabe, no entanto, discutir o grau de apoio à democracia e como o nível de insatisfação com o seu funcionamento, numa sociedade com enormes desigualdades sociais, pode, ou não, vir a comprometer sua legitimidade ao longo do tempo.

\footnotetext{
4 Este debate pode ser encontrado, em vários autores, como: Moisés (1995), Reis (2002), Baquero (2003) e Przeworski et al (2003). Estes últimos, ao reconstituirem o debate com base nas abordagens acima mencionadas, afirmam: "Na visão 'não-culturalista', a cultura não exerceria poder causal para explicar a democracia. Um país não necessitaria de uma cultura democrática para estabelecer instituições democráticas nem para sustentá-las. Uma segunda resposta possível, o ponto de vista 'culturalista fraco', sustenta que uma cultura democrática seria necessária para que uma democracia surja e se mantenha, mas a questão da compatibilidade dessa cultura com as tradições de sociedades particulares seria controversa, pois essas tradições seriam maleáveis, sujeitas a serem inventadas e reinventadas. Desse modo, uma cultura democrática poderia florescer mesmo em ambientes culturais aparentemente hostis. Por último, a visão 'culturalista forte' postula que algumas culturas seriam incompatíveis com a democracia. Em conseqüência, diferentes países deveriam buscar arranjos políticos distintos" (PRZEWORSKI et al, 2003, p.9).
} 


\section{Apoio à Democracia, Instituições e Direitos no Brasil}

As considerações encetadas neste artigo têm como referência empírica os dados resultantes do Estudo Eleitoral Brasileiro (ESEB), realizado em 2002, logo após o segundo turno da eleição presidencial. Foram entrevistadas 2.513 pessoas em todas as regiões do país, para configurar, assim, uma amostra representativa da sociedade brasileira.

Em primeiro lugar, faremos uma caracterização geral dos entrevistados em termos de distribuição por sexo, nível de escolaridade e situação ocupacional para então analisarmos os demais resultados da pesquisa.

Dentre os entrevistados, $47,1 \%$ são do sexo masculino e $52,9 \%$ do sexo feminino. No que se refere ao nível de escolaridade, um percentual considerável é composto por analfabetos (7,5\%), enquanto apenas $15 \%$ chegaram ao ensino superior. Os números relativos à Educação Básica também apontam o baixo índice de acesso à escolaridade formal no país: 46,8\% dos entrevistados tiveram acesso apenas ao ensino fundamental e 27,4\% ao ensino médio. Quanto à situação profissional e ocupação, há o predomínio de três categorias, a saber: empregados assalariados (36,1\%), autônomos (23,7\%), e donas de casa (12\%). Os aposentados e desempregados representam, respectivamente, $10 \%$ e 6,8\% da amostra.

As perguntas escolhidas para serem utilizadas na discussão do eixo temático - o apoio à democracia - refletem a direção de análise proposta e objetivam fundamentalmente contribuir com as demais reflexões proporcionadas pelo ESEB.

A democracia é percebida por 80,4\% como "mesmo com problemas, a melhor forma de governo". Isso nos leva a inferir que existe, na sociedade, um apoio disseminado à democracia. Esse apoio apresenta, em uma perspectiva comparada, uma tendência de crescimento, se confrontarmos com os dados apresentados por Baquero (2002). Segundo este autor, o nível de apoio à democracia no Brasil no ano de 2000 era de 39\%, o mais baixo entre os países latino-americanos pesquisados $^{5}$. Esse apoio disseminado à democracia, nos diversos segmentos da sociedade, permite sugerir que existe uma certa rejeição a formas autoritárias de exercício do poder.

No entanto, o nível de insatisfação com a democracia no Brasil é bastante significativo: $62,4 \%$ dos respondentes estão pouco ou nada satisfeitos com o seu funcionamento no país. Este dado é preocupante, uma vez que os altos índices de insatisfação podem, a longo prazo, comprometer seu apoio, ainda que a democracia tenha sido apontada como a melhor forma de governo.

\footnotetext{
${ }^{5}$ Nos demais países os índices eram os seguintes: Argentina, 71\%; Bolívia, 62\%; Colômbia, 50\%; Chile, 57\%; Equador, 54\%; México, 45\%; Paraguai, 48\%; Peru, 64\%; Uruguai, 84\%; Venezuela, $61 \%$.
} 
No mesmo diapasão, ao serem indagados se faz alguma diferença quem governa o país, $58 \%$ dos entrevistados responderam de maneira afirmativa. No entanto, a maioria $(65,3 \%)$ acredita apenas em parte que seu voto influencie o que acontece no país. Assim, a credibilidade do voto parece também comprometida e $45 \%$ dos entrevistados afirmam que não votariam caso o voto não fosse obrigatório.

No entanto, parece não haver uma tendência muito clara no que diz respeito à participação no processo político-eleitoral. Assim, 45,6\% dos entrevistados concordam que as eleições presidenciais ajudam muito a melhorar a vida da população; 40,1\% afirmam que ajudam um pouco mas 14,3\% declaram não haver qualquer melhoria, conformando uma divisão entre os que valorizam as eleições presidenciais e os que não acreditam nos seus resultados. Em conjunto, os dados sugerem que, muito provavelmente, uma correlação positiva dependerá da reversão das enormes desigualdades sociais existentes.

Young (apud BAQUERO, 2003, p. 89) analisando essas questões, afirma que vivemos hoje um momento paradoxal, na medida em que todos (ou uma extensa maioria) se dizem favoráveis à democracia, porém não acreditam que um governo democrático "possa fazer alguma coisa". Assim, até que os resultados da democracia sejam mais tangíveis, o quadro esboçado por Young tende a permanecer estável ou mesmo a mostrar sinais de um decréscimo nas opiniões favoráveis à democracia.

Quando indagados sobre a melhor forma de resolver os problemas do Brasil, $58 \%$ dos entrevistados optam pela participação da população nas decisões importantes, o que denota a valorização de mecanismos democráticos de participação. Todavia, $42 \%$ escolhem como melhor forma a atuação de um líder que "colocasse as coisas no lugar". Essa perspectiva se contrapõe à primeira e mais uma vez torna clara uma divisão entre as tendências observadas nas respostas dos entrevistados. Constata-se uma certa polarização entre aqueles que têm uma perspectiva de valorização dos mecanismos efetivos de participação política e aqueles que vêem na atuação de um grande líder a solução dos problemas. Uma perspectiva voluntarista ou populista não é, portanto, descartada para $42 \%$ dos entrevistados.

A personificação de um líder para resolver os problemas do país aparece também nas respostas sobre qual deve ser o fator fundamental para a escolha de um determinado candidato a presidente. Para 53,5\% dos entrevistados, deveria ser aquele que trouxesse mais benefícios à população e 29,5\% apontam que deveria ser aquele que estivesse disposto a combater os verdadeiros males do país.

Nesse sentido, vale lembrar a discussão sobre as novas democracias feita por O’Donnel (1992) na qual identifica a predominância de um viés fortemente delegativo na representação política, em detrimento do que pressupõe a idéia de accountability, ou seja, os controles horizontais e verticais de prestação de contas. 
Para o caso brasileiro e com o objetivo de apresentar considerações de caráter mais geral em relação aos resultados apresentados pela pesquisa, analisamos a seguir os dados relacionados à avaliação da atuação de algumas instituições, do acesso a direitos e à cidadania. Pretendemos, com isso, verificar em que medida a satisfação do entrevistado com as instituições democráticas ajuda a entender seu papel na melhoria de suas condições de vida. Mais da metade dos entrevistados são insatisfeitos com a atuação da justiça, que é considerada ruim por $32,5 \%$ e péssima por $20,5 \%$.

Sobre os partidos políticos, $57 \%$ dos entrevistados revelam não confiar em sua atuação, sendo que $37,3 \%$ a avaliam como ruim e 19,7\% como péssima. É também muito significativo que $90 \%$ se considerem pouco ou nada respeitados em seus direitos e liberdades.

Em conjunto, os dados evidenciam a percepção de uma cidadania restrita, uma vez que o funcionamento de várias instituições que deveriam garantir o seu exercício é considerado insatisfatório pela extensa maioria. $\mathrm{O}$ acesso às liberdades individuais e a confiança nas instituições, restritos a uma minoria, tornam-se um privilégio e não um direito. Held (1996) analisa a crítica que os adeptos da chamada Nova Esquerda fazem à ênfase dada à existência formal de direitos sem a contrapartida real, ou seja, sem que sejam de fato exercidos. Essa ressalva ou crítica é bastante pertinente no caso brasileiro, uma vez que os entrevistados percebem uma distância acentuada entre os direitos formais e o acesso a eles, garantido apenas para uma minoria, o que provoca um aprofundamento ainda maior das desigualdades existentes na sociedade brasileira.

O terceiro indicador a ser analisado neste artigo diz respeito ao maior problema do Brasil nos últimos quatro anos. A partir desta indagação, os entrevistados apontaram o desemprego em primeiro lugar $(37,5 \%)$ e, em seguida, mas de forma razoavelmente distante, a violência $(11 \%)^{6}$.

Esses dados ganham importância e coerência no conjunto de perguntas que propõem ao entrevistado que estabeleça as ações que seriam mais importantes para melhorar o Brasil. Gerar empregos sempre aparece como a ação prioritária, quando contrastada com a importância de combater a fome, controlar a inflação e fazer a economia crescer.

A percepção do desemprego como o maior problema do país não é uma preocupação apenas retórica. Quase um terço dos entrevistados já vivenciou tal situação: $30 \%$ dos entrevistados mencionaram ter vivido a experiência do desemprego nos últimos seis meses e o mesmo percentual afirma a preocupação em ficar desempregado nos seis meses seguintes.

\footnotetext{
6 Como já foi mencionado, a pesquisa foi realizada no segundo semestre de 2002. A pergunta mencionada fazia referência ao período 1998-2002.
} 
Uma pesquisa realizada em março de 2004 mostra que o desemprego continua sendo percebido como o maior problema e apresenta tendência ascendente: $49 \%$ dos entrevistados apontam o desemprego como o maior problema do país e mencionam em seguida a fome (12\%), a violência e a segurança $(11 \%)^{7}$.

Uma das variáveis explicativas para esse problema, reiteradamente apontada, seria a queda, ou mesmo a retração, das taxas de crescimento econômico. Em 2003, o PIB registrou um recuo de 0,2\%. Na verdade, desde os anos oitenta, as taxas de crescimento econômico do país têm sido bastante tímidas. A economia nacional, que já esteve em oitavo lugar no ranking mundial, regrediu para a décima quinta posição.

Diante desse panorama, não são inusitados os dados de uma pesquisa realizada pela ONU em vários países da América Latina, dentre eles o Brasil. De acordo com os resultados, 56,3\% crêem que o desenvolvimento econômico seja mais importante que a democracia e, neste sentido, 54,7\% afirmaram que apoiariam um governo autoritário se este resolvesse os problemas econômicos ${ }^{8}$.

A busca pelo entendimento desse amplo mosaico sobre o apoio e a credibilidade da atuação das instituições democráticas existentes no Brasil evidencia que há um apoio difuso à democracia. Os riscos de uma regressão autoritária também parecem descartados ou são, no máximo, bastante remotos. Todavia, em seu conjunto, os dados aqui analisados mostram que as instituições democráticas não têm sido capazes de gerar níveis satisfatórios de credibilidade quanto ao seu funcionamento, nem de cumprir as promessas feitas durante a transição política. Se somarmos a isso os altos índices de desemprego e desigualdade social presentes na sociedade brasileira, podemos vislumbrar um quadro bastante desolador: a existência de um enorme fosso social entre o país formal e o país real, onde vive a maioria dos brasileiros.

Não se pode contestar que o regime democrático, do ponto de vista da engenharia dos procedimentos, seja uma realidade. Para conquistar, porém, a adesão decisiva da população e consolidar uma cultura política democrática é necessário estender a democracia para além dos procedimentos formais, produzindo a confiança dos cidadãos em sua eficácia.

\footnotetext{
7 Dados de pesquisa realizada pelo Datafolha, publicados no jornal Folha de São Paulo em 08/03/2004. A pesquisa ouviu 2.036 pessoas em 132 municípios brasileiros no dia primeiro de março de 2004. A reportagem que acompanhava a pesquisa afirmava que o percentual verificado nesta pesquisa era o mais alto desde janeiro de 1999, na gestão do ex-presidente Fernando Henrique Cardoso (1995-2002), quando o desemprego foi apontado como o maior problema do Brasil por $53 \%$ dos entrevistados.

${ }^{8}$ Os resultados da pesquisa mencionada foram publicados no jornal Folha de São Paulo em 21/04/2004. Os pesquisadores fizeram a seguinte pergunta: "Você apoiaria um governo autoritário se ele pudesse resolver os problemas econômicos?". A pesquisa foi realizada em 18 países da América Latina, dentre eles, Brasil, México, Chile, Argentina, Uruguai, Venezuela, Colômbia e Paraguai.
} 


\section{Bibliografia}

ALMOND, A. \& VERBA, S. La Cultura Política. Diez Textos Básicos de Ciencia Política. Barcelona: Ariel,1992.

BAQUERO, M. Democracia, Cultura e Comportamento Político: uma análise da situação brasileira. In: FUKS, M. e PERISSINOTO, R. M. (orgs.). Democracia Teoria e Prática. Rio de Janeiro: Relume Dumará, 2002.

Construindo uma outra sociedade: o capital social na estruturação de uma cultura política participativa no Brasil. Revista Sociologia e Política, n² 21, p. 83-108, nov. 2003.

DAHL, R. Poliarquia. São Paulo: Edusp, 1997.

HELD, D. Models of democracy. Stanford: Stanford University Press, 1996.

MOISÉS, J. A. Os Brasileiros e a Democracia: Bases sócio-políticas da legitimidade democrática. São Paulo: Ática, 1995.

O'DONNEL, G. Delegative Democracy. Kellog Institute Working Papers, nº 192, 1992.

O'DONNEL, G. e REIS, F. W. A Democracia no Brasil: Dilemas e Perspectivas. São Paulo: Vértice, 1988.

PRZEWORSKI, A.; LIMONGI, F. e CHEIBUB. J. A. Democracia e Cultura: Uma visão não culturalista. Lua Nova, $n^{\circ}$ 58, 2003.

REIS, E. Pobreza, desigualdade e identidade política. In: REIS, E. Processos e escolhas: estudos de sociologia política. Rio de Janeiro: Contra Capa, 1998.

REIS, F. W. Democracia, igualdade e identidade. In: FUKS, M. e PERISSINOTO, R. M. (Orgs.). Democracia: teoria e prática. Rio de Janeiro: Relume Dumará, 2002.

SADER, E. Quando novos personagens entraram em cena: experiência, fala e lutas dos trabalhadores na Grande São Paulo 1970/1980. Rio de Janeiro: Paz e Terra, 1988.

SINGER, P. et al. São Paulo: o povo em movimento. Petrópolis: Vozes, 1980.

SCHMITTER, P. O'DONNEL, G. e WHITEHEAD, L. Transições do Regime Autoritário. São Paulo: Vértice, 1988. 